\title{
Adaptation in Response of Excitation and Inhibition Factors of Angiogenesis after 4 Weeks of Progressive Resistant Training in Sedentary Men
}

\author{
Karami S.* MSc, Ramezani A.R. ${ }^{1}$ PhD \\ *Sport Physiology Department, Physical Education \& Sport Sciences Faculty, \\ Training Shahid Rajaee University of Tehran, Tehran, Iran \\ ${ }^{1}$ Sport Physiology Department, Physical Education \& Sport Sciences Faculty, \\ Training Shahid Rajaee University of Tehran, Tehran, Iran
}

\begin{abstract}
Aims: The sport activity is an important factor affecting the capillary density and angiogenesis. Nitric oxide (NO) and vascular endothelial growth factor (VEGF) are the most important stimulative regulators in the angiogenesis. In addition, endostatin is one of the inhibitors of angiogenesis. The aim of this study was to investigate the adaptation in the responses of the angiogenesis inhibition and stimulating factors after 4-week increasing resistive exercises in the sedentary men.

Materials \& Methods: In the semi-experimental study, 20 healthy and inactive male students, aged between 20 and 25 years, who were residents of Tehran University Dormitory, were studied in the first semester of the academic year 2015-16. The subjects, selected via available sampling method, were divided into two groups including experimental and control groups ( $\mathrm{n}=10$ per group). 4-week resistive exercises were done three sessions per week. Blood-sampling was done before and 48 hours after the last exercise session. VEGF, NO, and endostatin were then measured. Data was analyzed by SPSS 18 software using independent and dependent T tests, as well as Pearson correlation coefficient test.

Findings: In experimental group, VEGF and No significantly increased at the posttest stage than the pretest $(p=0.001)$. Nevertheless, no significant difference was observed in control group ( $\mathrm{p}>0.05)$. In both experimental and control groups, endostatin level did not significantly increase at the posttest stage than the pretest $(p>0.05)$. In addition, VEGF and NO were the only variables that were significantly correlated $(p=0.016 ; r=0.82)$.

Conclusion: 4-week increasing resistive exercises in the sedentary men significantly affect the angiogenes stimulating factors, i. e. VEGF and NO, while such exercises do not significantly affect the angiogenesis inhibition factor, i. e. endostatin.
\end{abstract}

\section{Keywords}

Angiogenesis [http://www.ncbi.nlm.nih.gov/mesh/68043925];

Nitric Oxide [http://www.ncbi.nlm.nih.gov/mesh/68009569];

Resistance Training [http://www.ncbi.nlm.nih.gov/mesh/68055070];

Vascular Endothelial Growth Factor [http://www.ncbi.nlm.nih.gov/mesh/68042461]

*Corresponding Author

Tel: +98 (26) 34329028

Fax: +98 (21) 22046067

Address: No. 14, Sport Physiology Department, Hamshahri Institute, Touraj Street, Valiasr Street, Tehran, Iran

karami.sp@gmail.com

Received: December 25, $2015 \quad$ Accepted: May 11, 2016 ePublished: October 1, 2016 


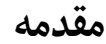

سازكارىهاى بسيارى بلهدنبال تمرينهاى ورزشى منظهم در بدن

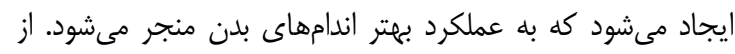

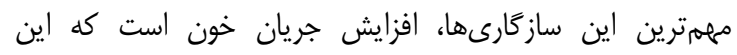

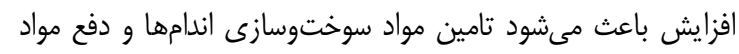

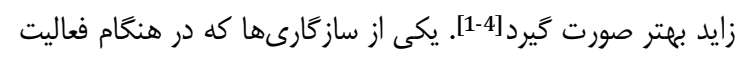

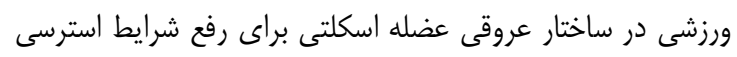

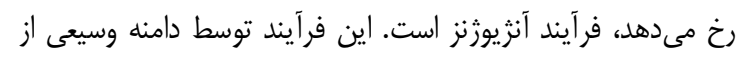

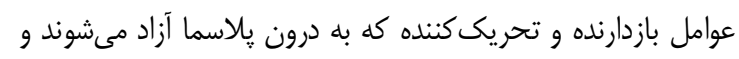

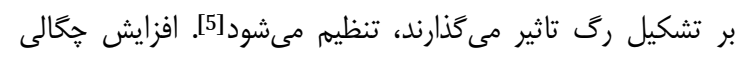

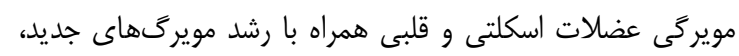

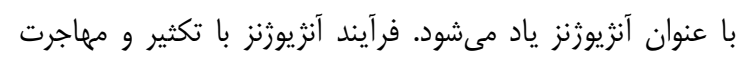

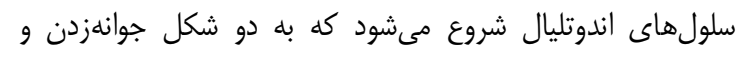

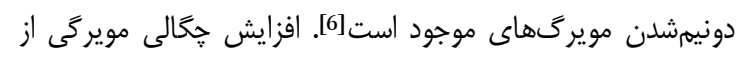

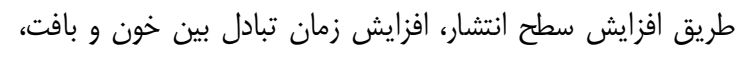

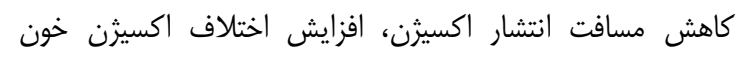

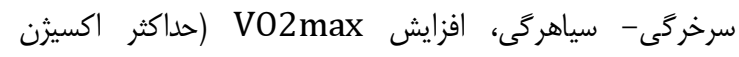

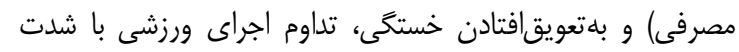

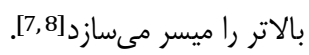

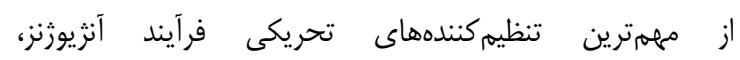
نيتريكاكسايد (NO) و فاكتور اندوتليال رشد عروقى (VEGF)

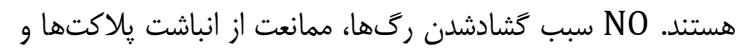

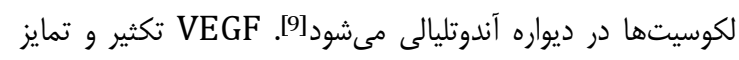

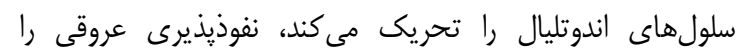

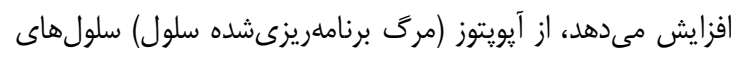

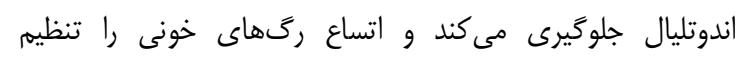

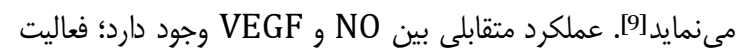
أيرنده فاكتور اندوتليال رشد عروقى (VEGFR2) توليد

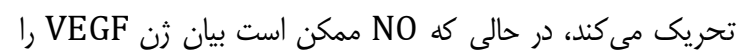

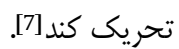
ديكر عامل تنظيمكننده فر آيند آنزيوزنز كه يك فاكتور مهارى است،

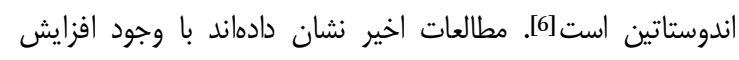

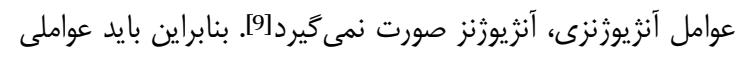

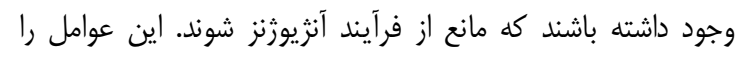

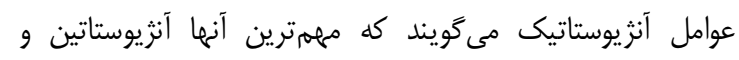

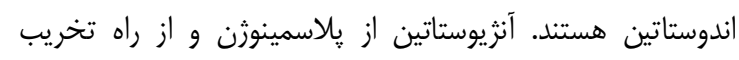

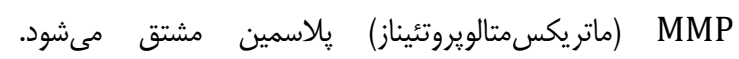

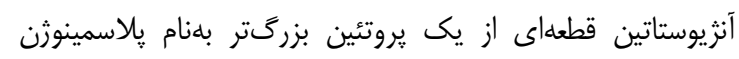

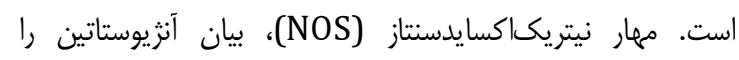

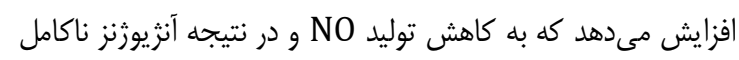

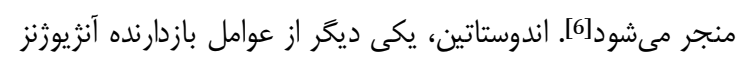

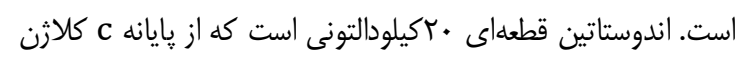

سازكارى در ياسخ عوامل تحريكى و مهان مهارى

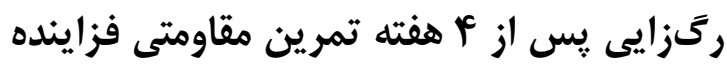

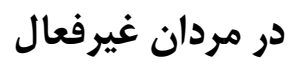

\section{MSc سجاد كرمى"}

كروه فيزيولوزى ورزش، دانشكده تربيت بدنى و علوم ورزشى، دانشكاه تربيت دبير شهيد رجايى، تهران، ايران

عليرضا رمضانى PhD

كَروه فيزيولوزى ورزش، دانشكده تربيت بدنى و و علوم ورزشى، دانشكاه تربيت دبير شهيد رجايى، تهران، ايران فرزئ

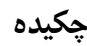

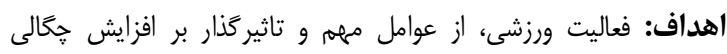

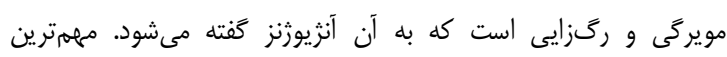

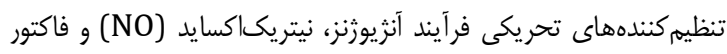

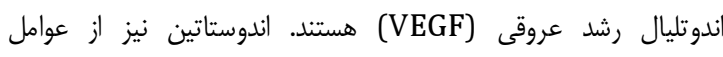

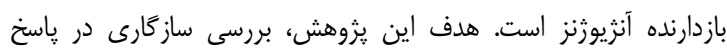

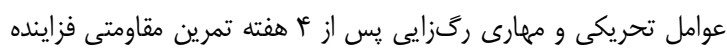
در مردان غيرفعال بود.

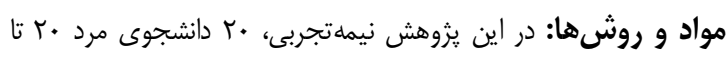

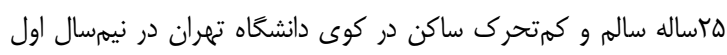

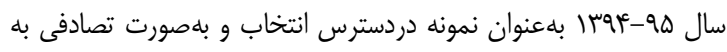

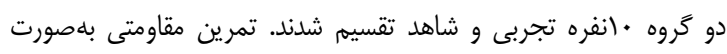

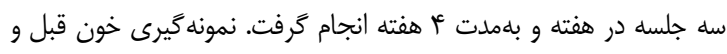

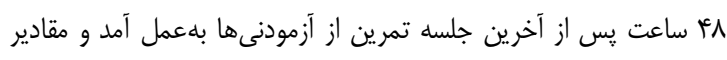
NO ،EGF

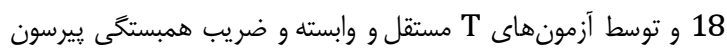
تحليل شدند.

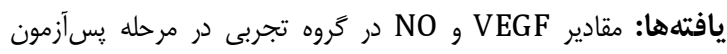

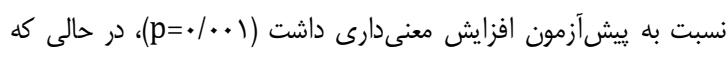

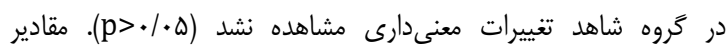

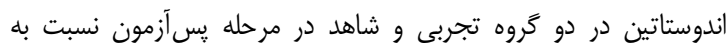

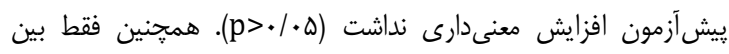

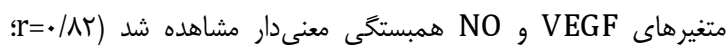
(p=./.19

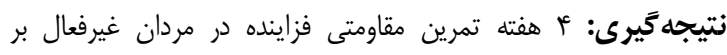

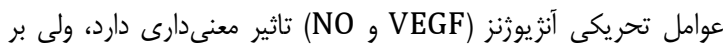
عامل مهارى آنزيوزنز (اندوستاتين) تاثير معنى دارى نداردي

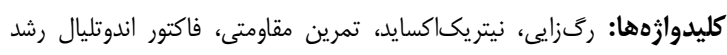

عروقى

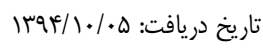

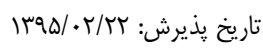
karami.sp@gmail.com :نويسنده مسئول: لتذيرث: 


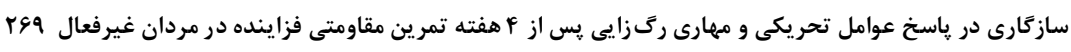

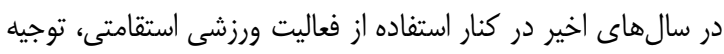
ACSM

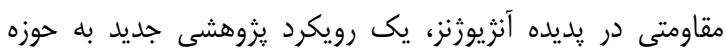
فعاليت ورزشى و سلامت معرفى كرده است. در يثوهشى كه آخديراً

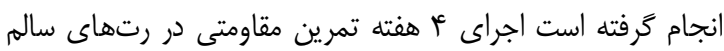

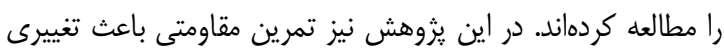

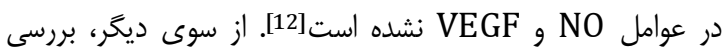
تاثير و هفته تمرين مقاومتى بر مقدار VEGF و اندوستاتين بافت

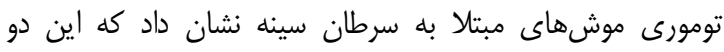

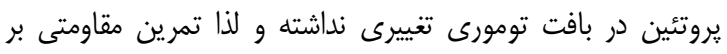

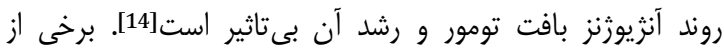

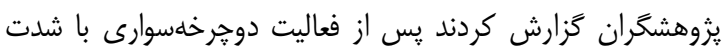

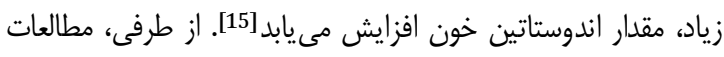
ديگر كه به بررسى تاثير يك وهله فعاليت ورزشى رونى روى مقادير

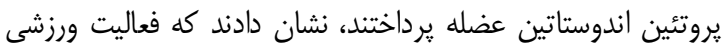

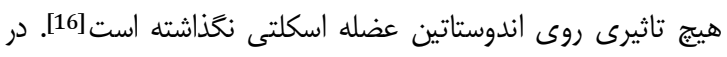

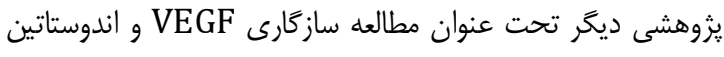

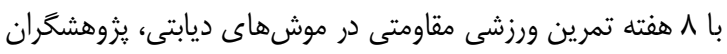

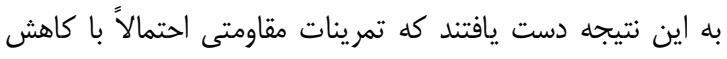

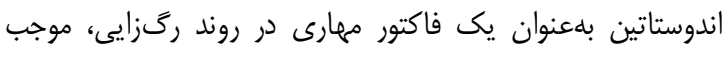

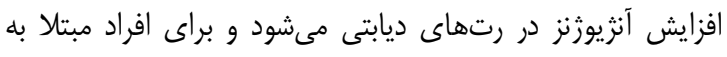

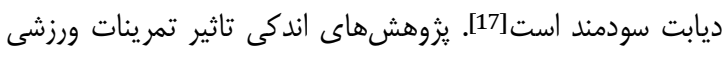
مقاومتى را روى مقادير NO NO و و اندوستاتين بررسى كردهاند. همجنين راهبردهاى استفاده از فعاليتهاى ورزشى مقاومتى در افر افراد

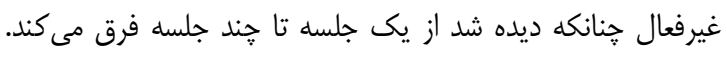

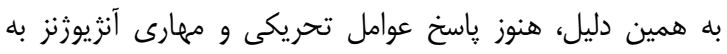
فعاليتهاى ورزشى مقاومتى مورد بحث و جدل است و يثروهشخران

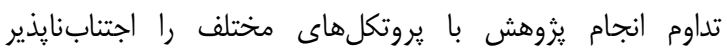
مى دانند.

از اين رو هدف اين يُوهش، بررسى سازگًارى در ياسخ عوامل

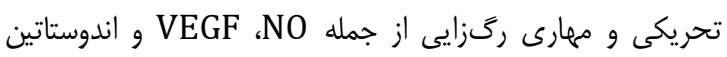

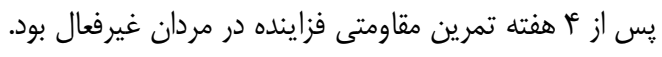

\section{مواد و روشها}

در اين يزوهش نيملتجربى كه بلشكل ميدانى با دو گروه تجربى و

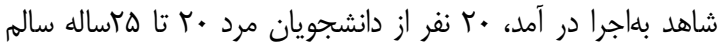
و كمتحرى ساكن در كوى دانشگاه تهران كه در نيهسال اول سال

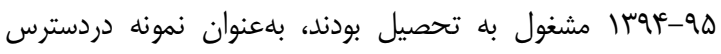

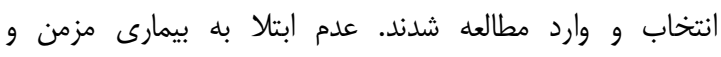

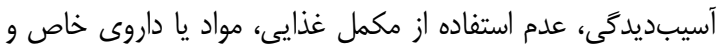

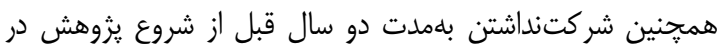

XVIII

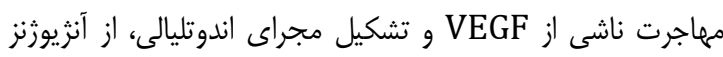

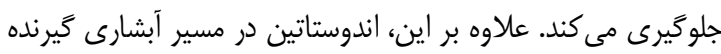
bFGF و VEGF اين طريق آنثيوزنز را مهار مى كند [6].

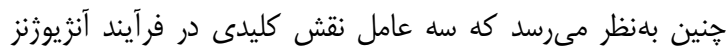

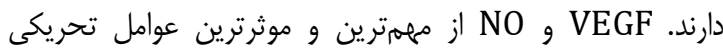

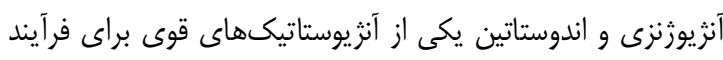

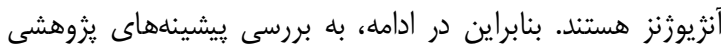

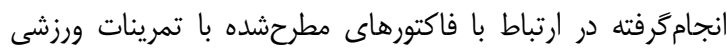

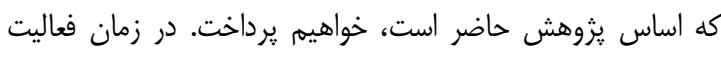

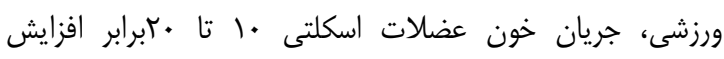

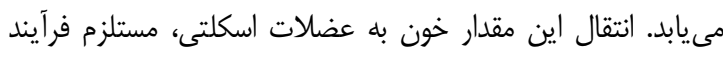

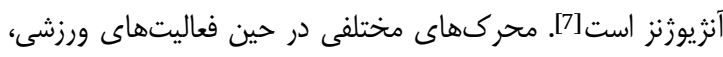

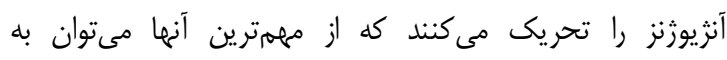

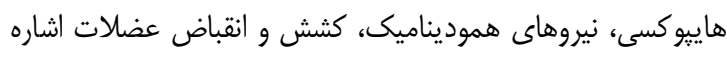

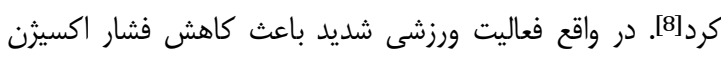

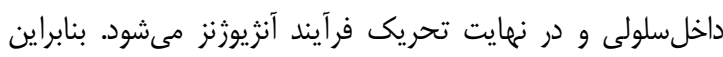

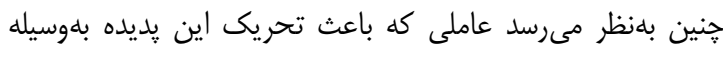

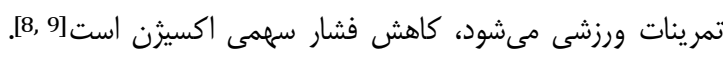

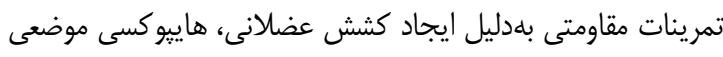

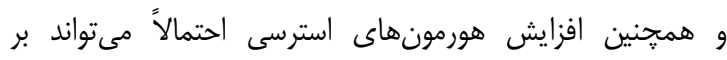
آنزيوزنز تاثير بخذارد.

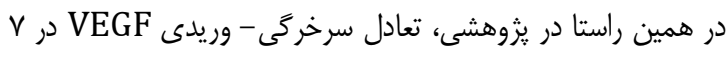

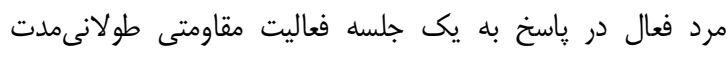

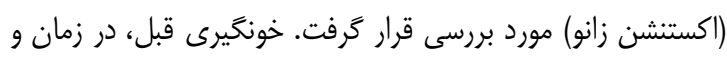

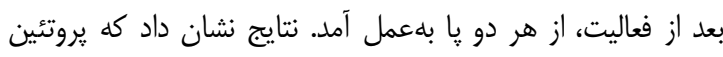

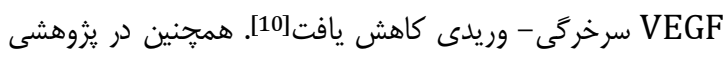

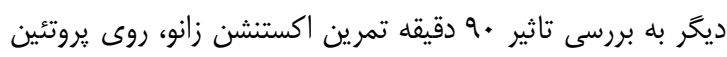

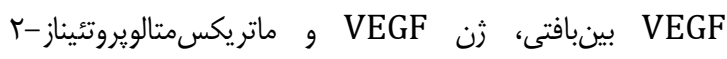
جوانان سالم يرداختند. نتايج تحقيق نشان داد يروتئين

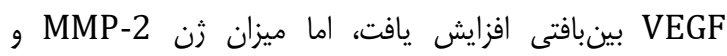

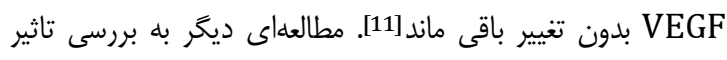

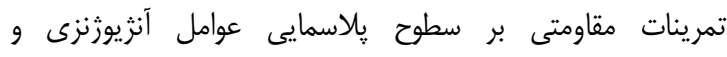

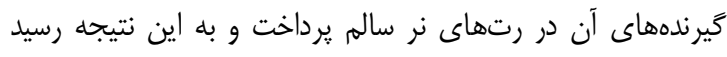

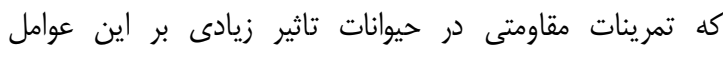

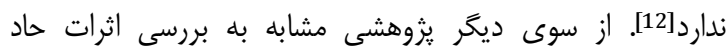

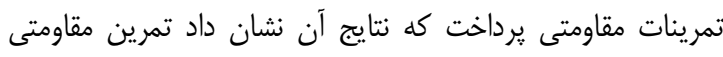

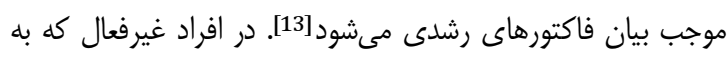

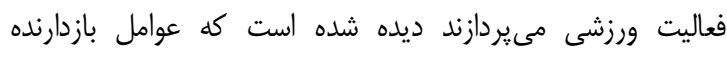

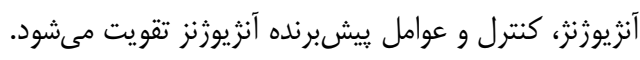


تمرينى ارزيابىهاى آنترويومتريك و نمونهكيرى خونى بلعمل آمد.

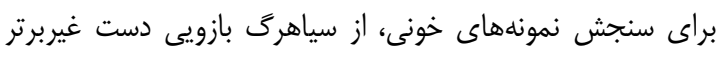

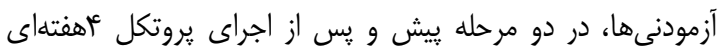

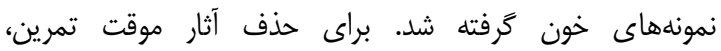

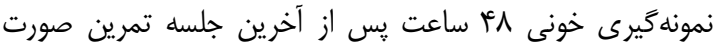
كرفت[19]. براى سنجش اندوستاتين از كيت الايزاى انسانى اندوستاتين با كد

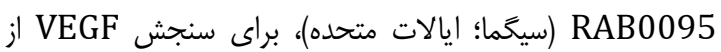
كيت الايزاى انسانى VEGF با كد

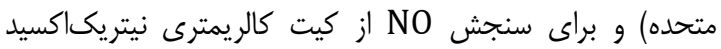

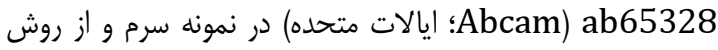

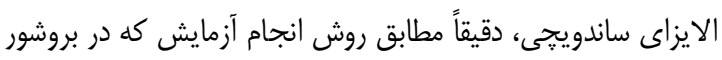
كيت توصيه شده بود، استفاده شد.

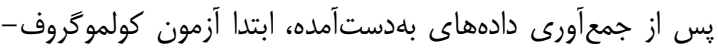
اسميرنوف براى بررسى طبيعىبودن توزيع دادهها و آزمون لوين

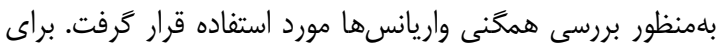
توصيف آمارى متغيرهاى وابسته از ميانكين و انحرافمعيار و براى آزمون فرضيههاى تحقيق از آزمونهاى T مستقل و و وابسته و النيف همجنين از ضريب همبستخى ييرسون براى بررسى رابطه بين ازين

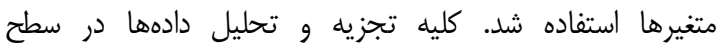

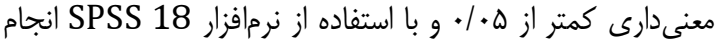

\section{يافتهها}

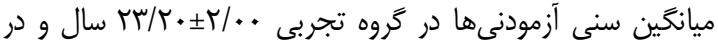

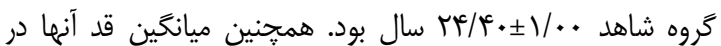

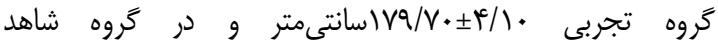

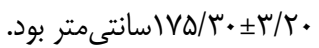

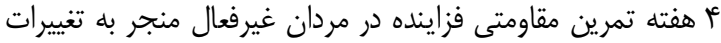

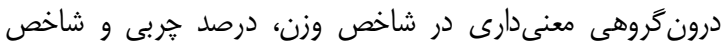

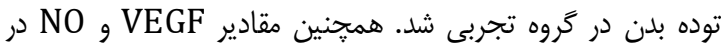
كروه تجربى در مرحله هِ

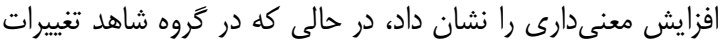

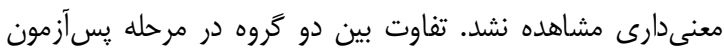

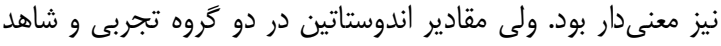

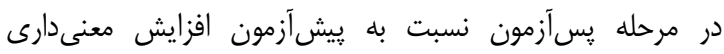
نداشت و تفاوت بين كروهى مقادير اندوستاتين نيز تغيير معنىدارى

را نشان نداد (جدول ().

تنها متغيرهاى VEGF و NO N و و بين ساير عوامل، همبستخى معنى دارى

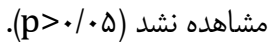

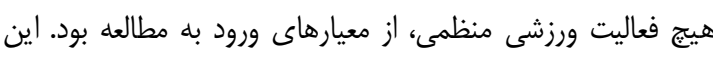
افراد بلهورت تصادفى به دو گروه • انفره تجربى و شاهد تقسيه

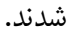

براساس اطلاعات بهدستآمده از يرسشنامه سابقه بزشكى و

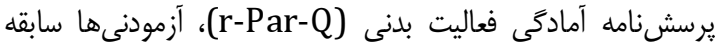

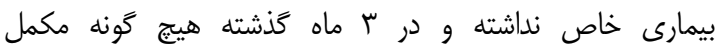
كربوهيدراتى، اسيدآمينهاى، كافئينى، آنتىاكسيدانى، الكل و تنباكو مصرف نكرده بودند. در ابتدا شرايط شركت در مطالعه، مشكلات احتمالى و تعداد دفعات

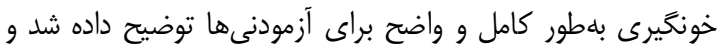

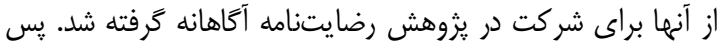

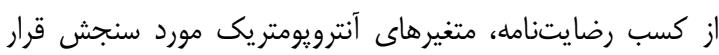

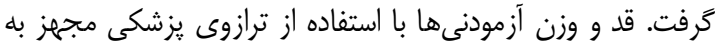

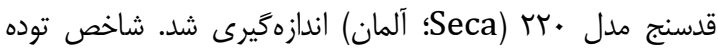

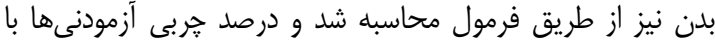

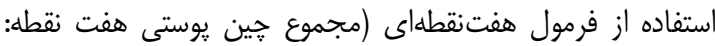

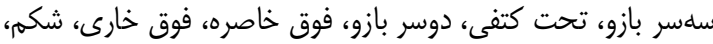

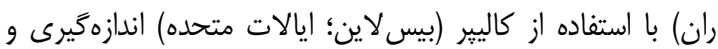

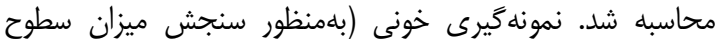

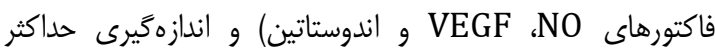
قدرت عضلات (يك تكرار بيشينه) از كروه تجربى بلمنظور تعديل

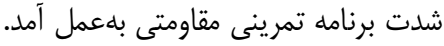

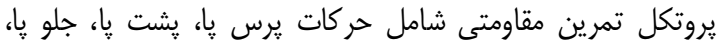

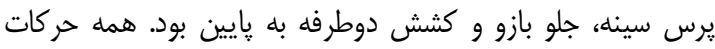

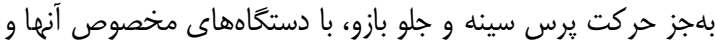

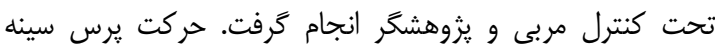

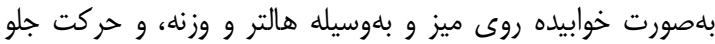
بازو بهوسيله هالتر و بلهصورت ايستاده كنار ديوار انجام شد. در اين اين إندان حركت بهدليل اينكه آزمودنىها مبتدى بودند، از آنها خواسته شد آندا كه براى انجام اين حركت ابتدا به ديوار تكيه بدهند و با خمانكردن إندان

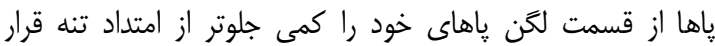

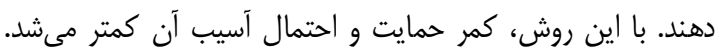

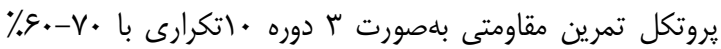

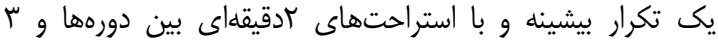

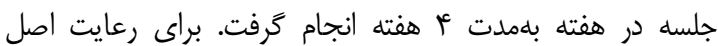

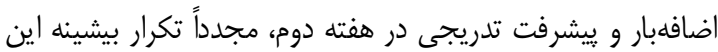

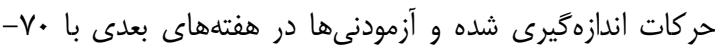

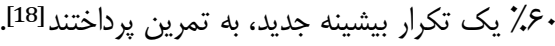

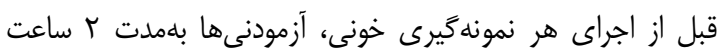

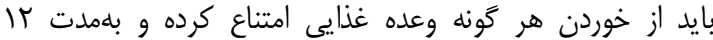

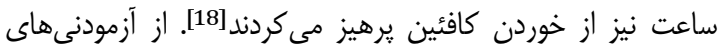
كروه تجربى و شاهد در دو مرحله شروع يروتكل و يايان يروتكل 


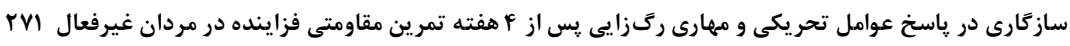

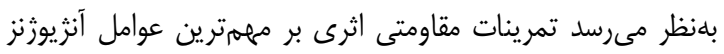

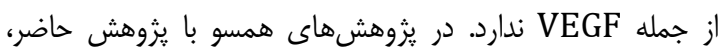

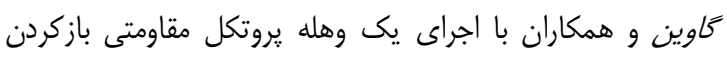

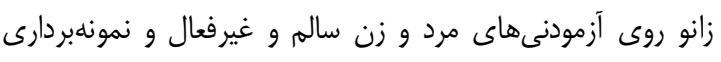

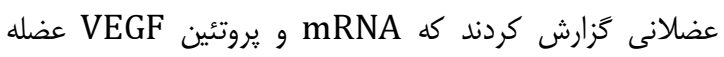

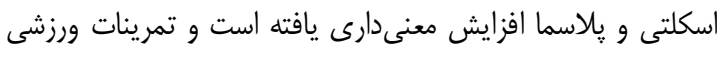

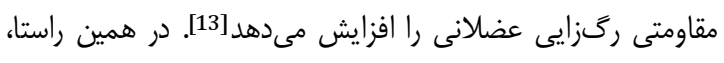

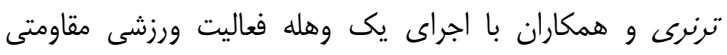

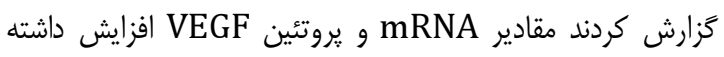

است[22]

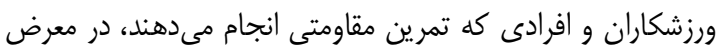

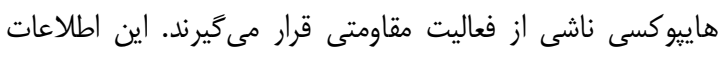

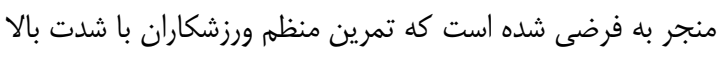

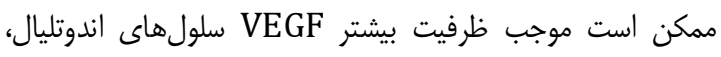

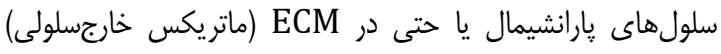

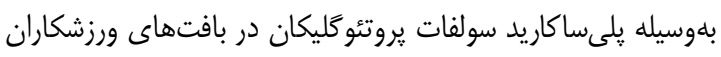

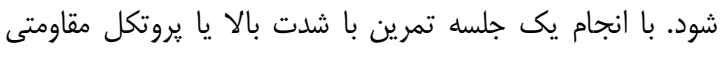

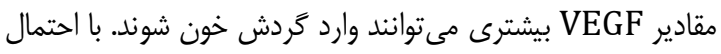

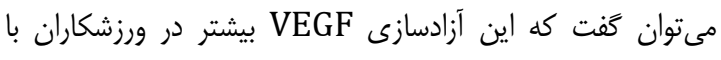

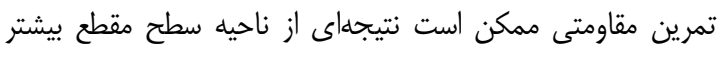
مويركَها در اين بافت عضله اسكلتى باشد [13].

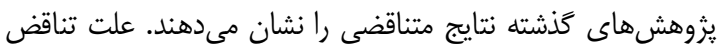

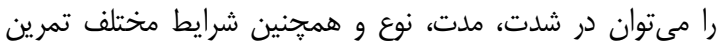

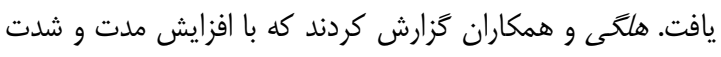
فعاليت ورزشى، جريان خون عضلات اسكلتى افزايش بيشترى

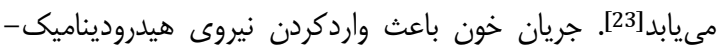

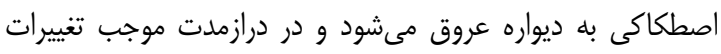

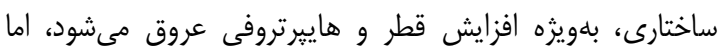

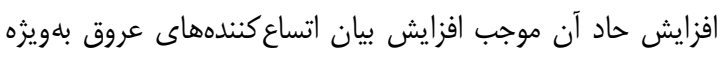

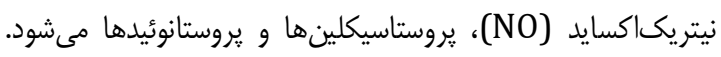

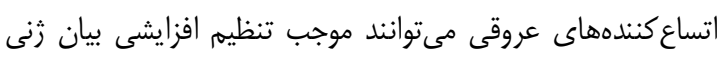

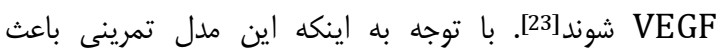

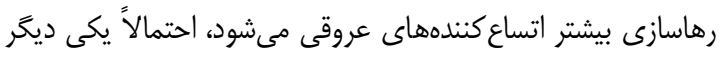

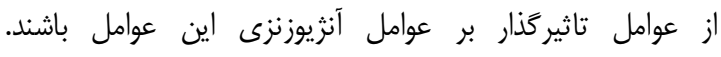

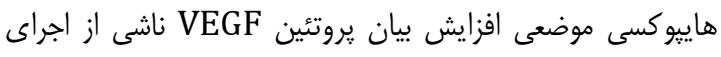

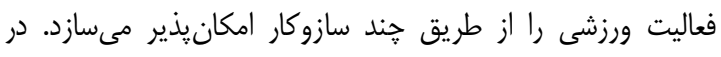

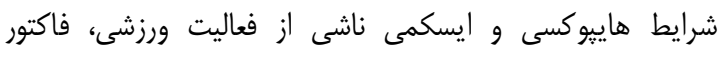

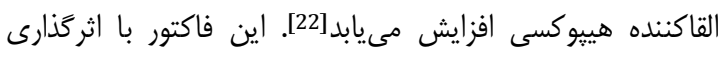

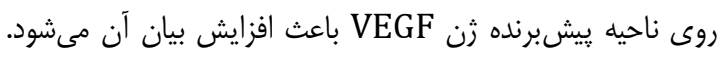

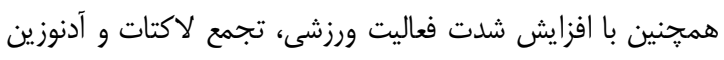

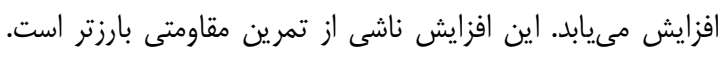

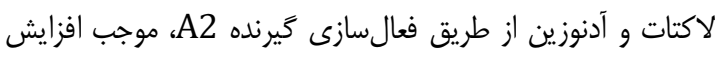

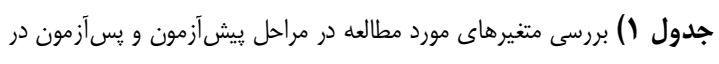

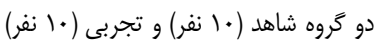

\begin{tabular}{|c|c|c|c|c|}
\hline معنى دين دارى & درون ترودارى & مر مَآزمون & يِيش آزمون & متغيرها \\
\hline \multicolumn{5}{|c|}{ وزن (كيلوَرم) } \\
\hline \multirow{2}{*}{$\cdot \% \Delta F$} & $.1 . .1$ & $V \cdot / V T \pm 1 / g^{\mu}$ & $99 / 11 \pm 1 / 49$ & تجربى \\
\hline & ./1rq & $s V / F) \pm r / \mu r$ & & شاهد \\
\hline \multicolumn{5}{|c|}{ "جربى (درصد) } \\
\hline \multirow{2}{*}{$.1 .+1$} & 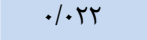 & $1 Q / 11 \pm \pm / 14$ & $|V / 8 \cdot \pm 1 / T|$ & 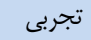 \\
\hline & $\cdot / \Delta \wedge \varepsilon$ & $r / I r \pm r / q r$ & $r T / \mathcal{A} \wedge \pm T / T r$ & 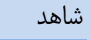 \\
\hline \multicolumn{5}{|c|}{ شاخص توده بدنى (كيلوَّرم بر مترمربع) } \\
\hline \multirow{2}{*}{$\cdot / \mathrm{VA}$} & $.1 .+1$ & $|q / r| \pm r / V \Delta$ & W/QV $\pm r / Q T$ & تجربى \\
\hline & . & $r r / 19 \pm r / 11$ & $r I / R \pm T / r r$ & شاهد \\
\hline \multicolumn{5}{|c|}{ VEGF (نانو گرم بر ميلىليتر) } \\
\hline \multirow{2}{*}{.$\% 11$} & $.1 .+1$ & $I V T / T \cdot \pm T V / T K$ & $|T N / \cdot \pm| N / Y q$ & تجربى \\
\hline & $\cdot / T \Lambda$ & $\mid r F / r \varepsilon \pm r q / r r$ & $|r V / 1 \cdot \pm r| / \& Q$ & شاهد \\
\hline \multicolumn{5}{|c|}{ اندوستاتين (نانوكرم بر ميلى ليتر) } \\
\hline \multirow{2}{*}{$\cdot /|V|$} &.$/ \cdot \Delta V$ & $V / G T_{ \pm T / R T}$ & $V / \& Y \pm I / r V$ & 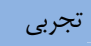 \\
\hline & $\cdot|\wedge|$ & $G / r T \pm T / A r$ & $\varepsilon / 9 \wedge \pm 1 / \wedge)$ & 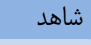 \\
\hline \multicolumn{5}{|c|}{ نيتريكاكسيد (ميكرومول بر ليتر) } \\
\hline \multirow{2}{*}{$.1 .+1$} &..+1 & $r E / V T+r / I V$ & $r r / / Q \pm T / \mu r$ & 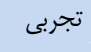 \\
\hline &.$/ 41$ & $r / D I \pm 2 / 1 r$ & $r / / I \pm r / I r$ & شاهد \\
\hline
\end{tabular}

بحث

نتايج تحقيق حاضر نشان داد كه f لم هفته تمرين مقاومتى منجر به

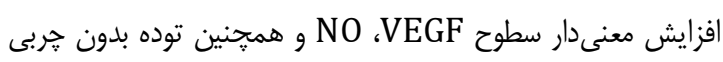

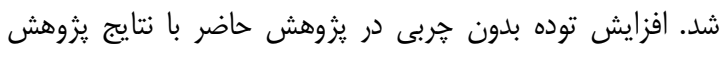

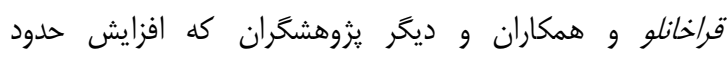

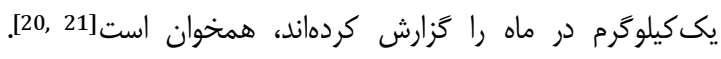

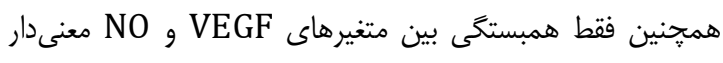

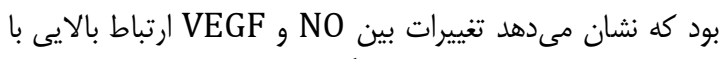

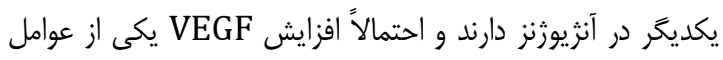

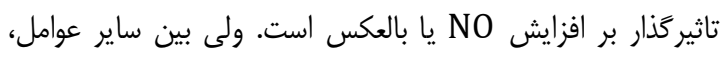
همبستخى معنى دارى مشاهده نشد.

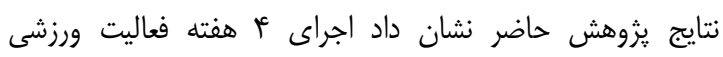

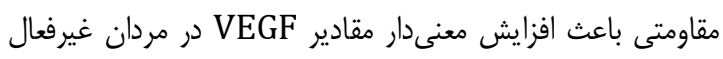

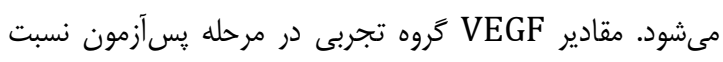

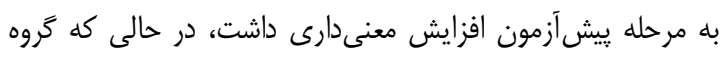

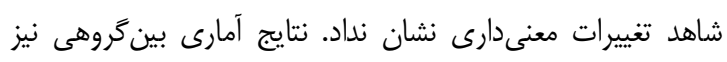

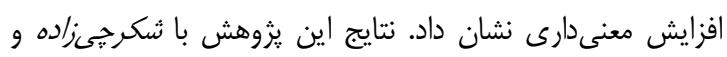

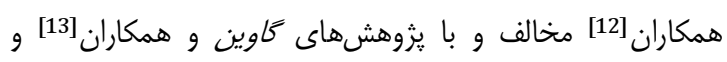

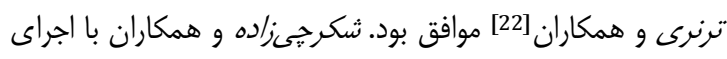

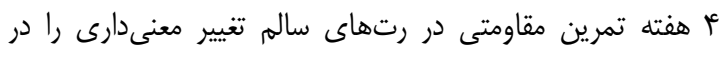

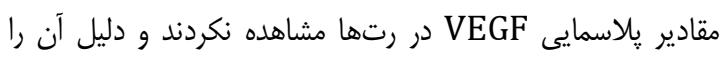
زمان و شدت تمرين و زمان خونخيرى اعلام و گزارش كردند [12]. 
وارده بر ديواره عروق و كشش سلولهاى آندوتليال باعث بازسازى آن

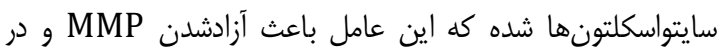

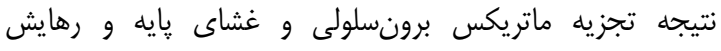

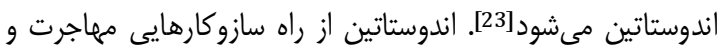

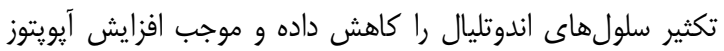

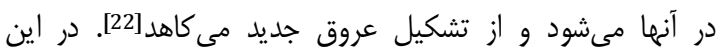
يزوهش بهنظر مىرسد كاهش اندوستاتين در كروه تمرين ورزشى آنى

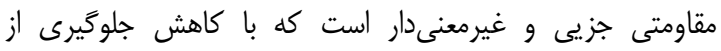

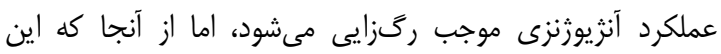

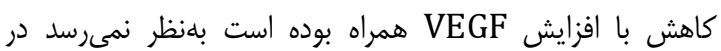
يثوهش حاضر عامل مهمى در فرآيند آنزيوزنز باشد.

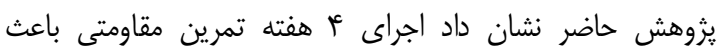

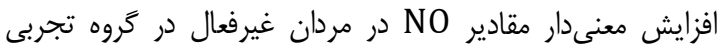

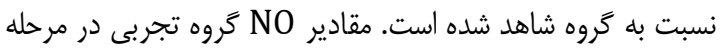

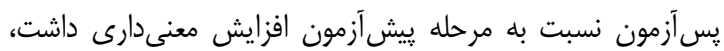

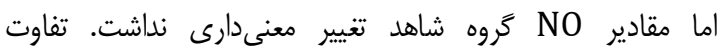
بينَّوهى نشان داد تمرين مقاومتى مىتواند باعث افزايش

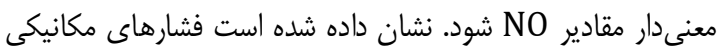

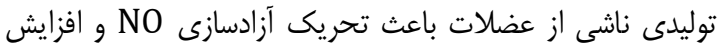
eNOS

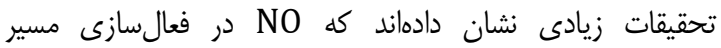

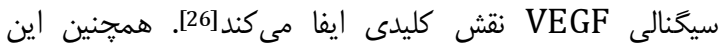
احتمال وجود دارد كه كشش سلولهاى اندوتليال باعث تجزيه

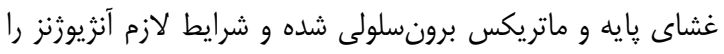

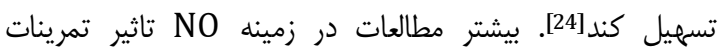

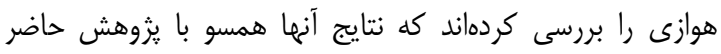

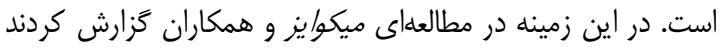

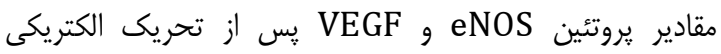
بلندمدت افزايش مىيابد[27]. لافلين و همكاران كزارش كردارت

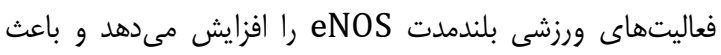

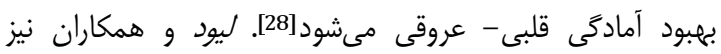

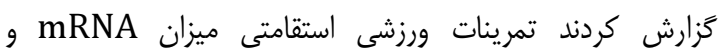

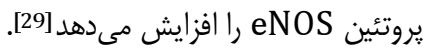

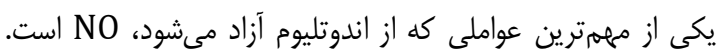

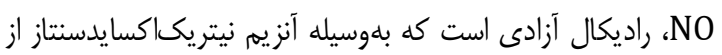

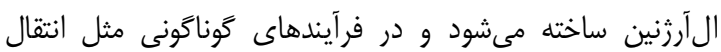
عصبى، اعمال عروقى، دفاع و التهاب دركير است.

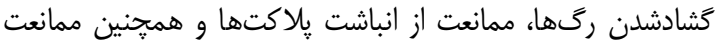

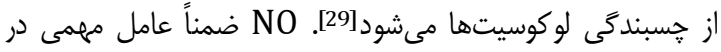

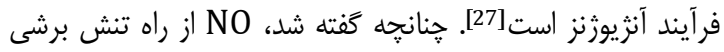

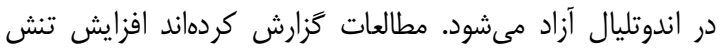
برشى هنگام شروع تكثير سلولهاى اندوتليال و فرآيند آنزيوثنز
غلظت cAMP و متعاقب آن افزايش سطوح mRNA VEGF

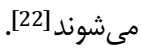

نيروهاى مكانيكى در تحريك VEGF و تغيير شكل شبكه عروق نقش دارند. جنانجه اكر در عروق جريكاني

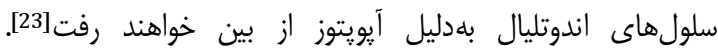

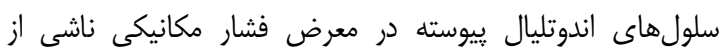

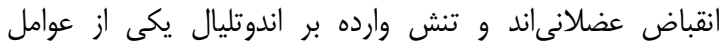

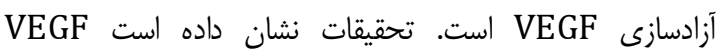

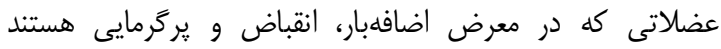

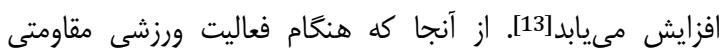
سلولهاى اندوتليال تحت كشش قرار مى ئيرند سرعت رهاسازى إنى VEGF

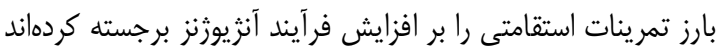

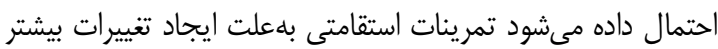
در دستخاه كردش خون محيطى و فعالسازى مسيرهاى وابسته به

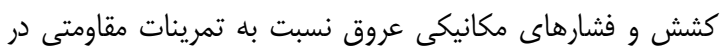
فرآيند آنزيوزنز موثرتر باشد. يروهش حاضر نشان داد اجراى عأ هفته تمرين مقاومتى باعث

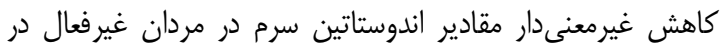

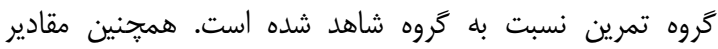

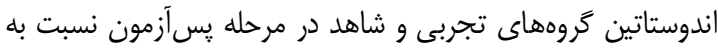

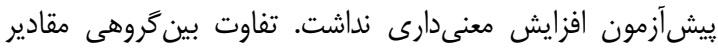

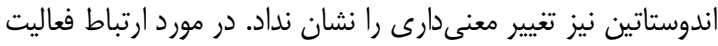
ورزشى مقاومتى و مقادير اندوستاتين تنها مطالعه انجامشده،

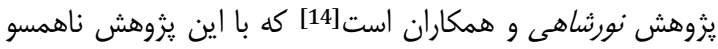

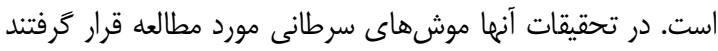
و كزارش شد مقادير اندوستاتين بافت سرطانى تغيير معنى دارى

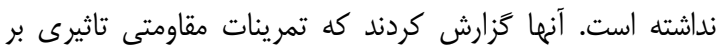

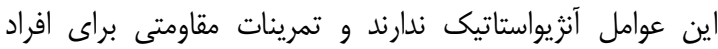

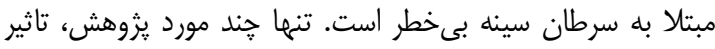

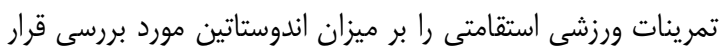

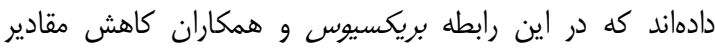

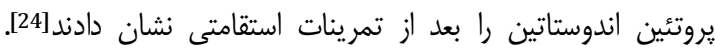

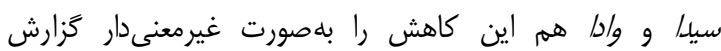

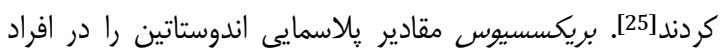

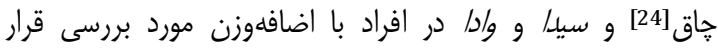
دادند[25]. كرجه مكانيزم ترشح اندوستاتين نامشخص است، اما بسيارى از

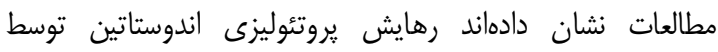

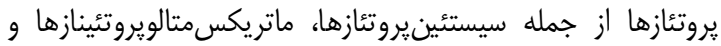

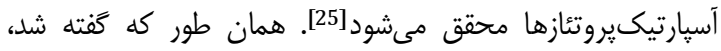
فشار مكانيكى هنكام فعاليت ورزشى بر اثر انقباض عضلانى و فنشار 


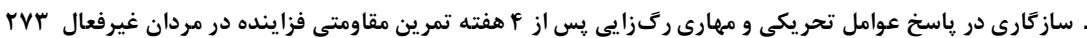

3- Lloyd PG, Prior BM, Li H, Yang HT, Terjung RL. VEGF receptor antagonism blocks arteriogenesis, but only partially inhibits angiogenesis, in skeletal muscle of exercise trained rats. Am J Physiol Heart Circ Physiol. 2005;288(2):H759-68.

4- Van Royen N, Piek JJ, Buschmann I, Hoefer I, Voskuil M, Schaper W. Stimulation of arteriogenesis: A new concept for the treatment of arterial occlusive disease. Cardiovasc Res. 2001;49(3):543-53.

5- Wood RE, Sanderson BE, Askew CD, Walker PJ, Green S, Stewart IB. Effect of training on the response of plasma vascular endothelial growth factor to exercise in patients with peripheral arterial disease. Clin Sci. 2006;111:4019.

6- Prior BM, Yang H, Terjung RL. What makes vessels grow with exercise training?. J Appl Physiol. 2004;97(3):1119-28.

7- Hepple RT, Hogan MC, Stary C, Bebout DE, MathieuCostello O, Wagner PD. Structural basis of muscle 02 diffusing capacity: evidence from muscle function in situ. J Appl Physiol. 2000;88(2):560-6.

8- Richardson RS, Wagner H, Mudaliar SR, Henry R, Noyszewski E, Wagner PD. Human VEGF gene expression in skeletal muscle: Effect of acute normoxic and hypoxic exercise. Am J Physiol. 1999;227(6 Pt 2):H2247-52.

9- Tang K, Xia FC, Wagner PD, Breen EC. Exerciseinduced VEGF transcriptional activation in brain, lung and skeletal muscle. Respir Physiol Neurobiol. 2010;170(1):16-22.

10- Hiscock N, Fischer C, Pilegaard H, Pedersen B. Vascular endothelial growth factor mRNA expression and arteriovenous balance in response to prolonged, submaximal exercise in humans. Am J Physiol Heart Circ Physiol. 2003;285(4):H1759-63.

11- Hellsten Y, Rufener N, Nielsen J, Hoier B, Krustrup P, Bangsbo J. Passive leg movement enhances interstitial VEGF protein, endothelial cell proliferation, and eNOS mRNA content in human skeletal muscle. Am J Physiol Regul Integr Comp Physiol. 2008;294(3):R975-82.

12- Shekarchizade P, Khazai M, Gharakhanlo R, Karimiyan J, Safarzade A. The effects of resistance training on plasma angiogenic factors in normal rats. J Medical Isfahan. 2012;30(176):65-73. [Persian] 13- Gavin TP, Drew JL, Kubik CJ, Pofahl WE, Hickner RC. Acute resistance exercise increases skeletal muscle angiogenic growth factor expression. Acta Physiol. 2007;191(2):139-46.

14- Nour Shahi M, Babai A, Ghasemi MR, Beyrami M. The effect of six weeks of resistance training on tumor tissue VEGF and endostatin in mice with breast cancer. Sci Sports. 2013;5(17):27-46. [Persian]

15-Suhr F, Brixius K, de Marées M, Bölck B, Kleinöder H, Achtzehn S, et al. Effects of short-term vibration and hypoxia during high-intensity cycling exercise on circulating levels of angiogenic regulators in humans. J Appl Physiol. 2007;103(2):474-83.

16- Rullman E, Rundqvist H, Wagsater D, Fischer H, Eriksson P, Sundberg CJ, et al. A single bout of exercise activates matrix metalloproteinase in human skeletal muscle. Appl Physiol. 2007;102(6):2346-51.

17- Mahrou M, Gaeini AA, Javidi M, Chobbineh S. Changes in stimulating factors of angiogenesis, induced by progressive resistance training in diabetic rats. Iran J Diabetes Metabol. 2014;14 (1):1-8. [Persian]

18- Griffin E, Mullally W, Foley S, Warmington C, OMara S. A. Aerobic exercise improves hippocampal function

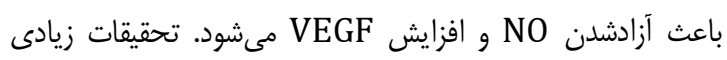

نشان دادهاند NO در فعالشدن مسير سيكنالى VEGF نقش

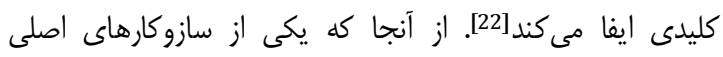
رهايش NO در عروق، تنش برشى است و در تمرينات مقاومتى

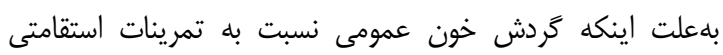

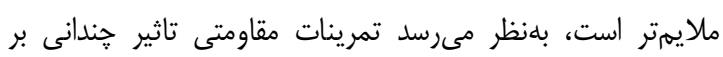

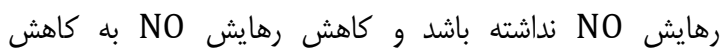
VEGF

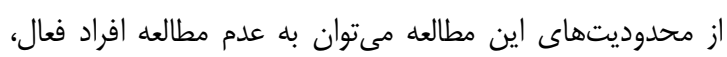

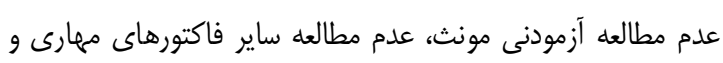

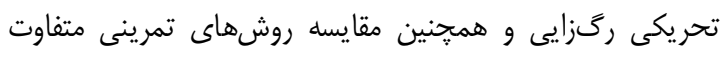
اشاره كرد. ييشنهاد مىشود با توجه به اينكه محققان نتايج

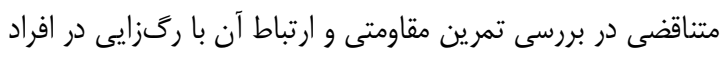
فعال و غيرفعال به دست آوردهاند، تحقيقات بيشترى در در اين زمينه

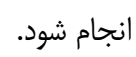
نتيجهل

F هفته تمرين مقاومتى فزاينده در مردان غيرفعال بر عوامل

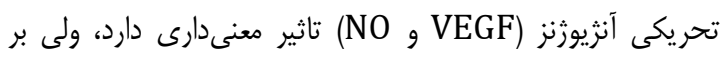
عامل مهارى آنزيوزنز (اندوستاتين) تاثير معنى دارى ندارد.

تشكر و قدردانى: بدين وسيله از كليه دوستان عزيزى كه

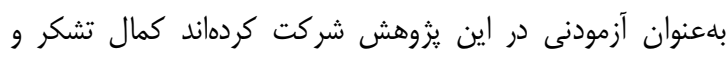
قدردانى را دارم. تاييديه اخلاقى: در ابتدا شرايط شركت در مطالعه، مشكلات

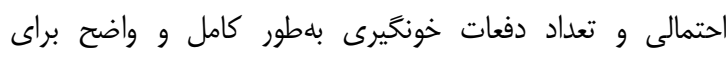

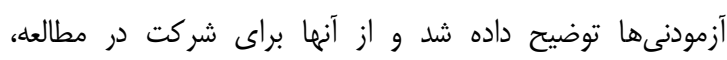
رضايتنامه آكَاهانه اخذ شد. تواند تعارض منافع: هيج گونه تعارض منافع توسط نويسندًان بيان نشده است. منابع مالى: اين :ثروهش با هزينه شخصى نويسندًان انجام كرفته است.

\section{منابع}

1- Gustafsson T, Knutsson A, Puntschart A, Kaijser L, Nordqvist SA-C, Sundberg C, et al. Increased expression of vascular endothelial growth factor in human skeletal muscle in response to short-term one-legged exercise training. Pflügers Arch. 2002;444(6):752-9.

2- Siafakas N, Jordan M, Wagner H, Breen E, Benoit $H$, Wagner P. Diaphragmatic angiogenic growth factor mRNA responses to increased ventilation caused by hypoxia and hypercapnia. Eur Respir J. 2001;17(4):6817. 
exercise decreases antiangiogenic endostatin signalling in overweight men aged 50-60 years. Br J Sports Med. 2008;42(2):126-9.

25- Seida A, Wada J, Kunitomi M, Tsuchiyama Y, Miyatake $\mathrm{N}$, Fujii M, et al. Serum bFGF levels are reduced in Japanese overweight men and restored by a 6-month exercise education. Int J Obes Relat Metab Disord. 2003;27(11):1325-31.

26- Loufrani L, Henrion D. Role of the cytoskeleton in flow (shear stress)-induced dilation and remodeling in resistance arteries. Med Biol Eng Comput. 2008;46(5):451-60.

27- Milkiewicz M, Hudlicka O, Brown MD, Silgram H. Nitric oxide, VEGF, and VEGFR-2: Interactions in activityinduced angiogenesis in rat skeletal muscle. Am J Physiol Heart Circ Physiol. 2005;289(1):H336-43.

28- Laughlin MH, Pollock JS, Amann JF, Hollis ML, Woodman CR, Price EM. Training induces nonuniform increases in eNOS content along the coronary arterial tree. J Appl Physiol. 2001;90(2):501-10.

29- Lloyd PG, Prior BM, Yang HT, Terjung RL. Angiogenic growth factor expression in rat skeletal muscle in response to exercise training. Am J Physiol Heart Circ Physiol. 2003;284(5):H1668-78.
سجاد كرمى و همكاران TVF

and increases BDNF in the serum of young adult males. Physiol Behav. 2011;104(5):934-41.

19- Qi Z, He J, Zhang Y, Shao Y, Ding S. Exercise training attenuates oxidative stress and decreases p53 protein content in skeletal muscle of type 2 diabetic GotoKakizaki rats. Free Radic Biol Med. 2011;50(7):794-800. 20- Gharakhanlo R, Saremi A, Omidfar K, Sharghi S, Gheraati MR. Effect of resistance training on myostatin, testestron and cortisol in young men. Olympic. 2008;16(3):42-55. [Persian]

21- Tesch PA, Ekberg A, Lindquist D, Trieschmann JT. Muscle hypertrophy following 5 week resistance training using a non gravity dependent exercise system. Acta Physiol Scand. 2004;180(1):89-98.

22- Trenerry MK, Carey KA, Ward AC, Cameron-Smith D. STAT3 signaling is activated in human skeletal muscle following acute resistance exercise. J Appl Physiol. 2007;102(4):1483-9.

23- Helge JW, Stallknecht B, Pedersen BK, Galbo H, Kiens B, Richter EA. The effect of graded exercise on IL-6 release and glucose uptake in human skeletal muscle. J Physiol. 2003;546:299-305.

24- Brixius $K$, Schoenberger S, Ladage D, Knigge $H$, Falkowski G, Hellmich M, et al. Long-term endurance 